\title{
Educação, povos do campo e pandemia da COVID-19: reflexões a partir de um projeto de extensão de uma universidade pública brasileira
}

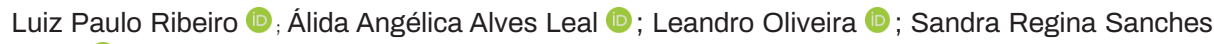 \\ Ribas (D) \\ Universidade Federal de Minas Gerais (UFMG), Brasil
}

\begin{abstract}
Resumo. O objetivo deste artigo foi analisar repercussões da pandemia da COVID-19 para a educação em comunidades rurais nas quais estudantes de Licenciatura em Educação do Campo (LECampo) de uma universidade pública brasileira trabalham e/ou residem. O estudo refere-se a um recorte de uma pesquisa mais ampla, articulada ao projeto de extensão "Povos do Campo e a pandemia da COVID-19", criado em abril de 2020. O percurso metodológico da investigação consistiu na aplicação de questionários online em dois momentos da pandemia no Brasil (abril/maio e julho de 2020). Tais instrumentos foram respondidos por 36 (trinta e seis) estudantes na primeira etapa e por 46 (quarenta e seis) estudantes na segunda etapa. Os dados foram analisados a partir dos dois momentos da pesquisa, descritos e comparados à literatura da área da Educação do Campo. Assim, no primeiro momento, foi notado um maior movimento de manter as escolas fechadas e, no segundo momento, foram observadas tentativas de instaurar um Ensino Remoto Emergencial com distribuição de materiais e aulas/contatos online. Evidenciamos que a pandemia expôs e acentuou as desigualdades na oferta escolar na rede pública brasileira, sobressaltando a precariedade histórica das políticas públicas destinadas à educação das populações campesinas.
\end{abstract}

Palavras-chave: educação do campo; pandemia; ensino remoto; COVID-19; Brasil.

Educación, pueblos rurales y pandemia de la COVID-19: reflexiones a partir de un proyecto de extensión de una universidad pública brasileña

Resumen. El objetivo de este artículo fue analizar las repercusiones de la pandemia de COVID-19 en la educación de comunidades rurales en las que trabajan y/o viven estudiantes de la Licenciatura en Educación del Campo (LECampo) de una universidad pública brasileña. El estudio se refiere a una parte de una investigación más amplia, articulada al proyecto de extensión " Pueblos del Campo y la pandemia de COVID-19 ", creado en abril de 2020. El recorrido metodológico de la investigación consistió en la aplicación de cuestionarios online en dos momentos de la pandemia en Brasil (abril/ mayo y julio de 2020). Contestaron a estos instrumentos 36 (treinta y seis) estudiantes en la primera etapa y 46 (cuarenta y seis) en la segunda. Se analizaron los datos de los dos momentos de la investigación, se describieron y se compararon con la literatura en el área de la Educación del Campo. Así, en un primer momento se notó un mayor movimiento para mantener las escuelas cerradas y, en un segundo momento, se observaron intentos de establecer una Educación Remota de Emergencia con distribución de materiales y clases/contactos online. Evidenciamos que la pandemia expuso y acentuó las desigualdades en la oferta escolar en la red pública brasileña, destacando la precariedad histórica de las políticas públicas destinadas a la educación de las poblaciones campesinas.

Palabras clave: educación rural; pandemia; educación remota; COVID-19; Brasil.

\begin{abstract}
Education, peasantry and pandemic of COVID-19: reflections from an extension project of a Brazilian public university

Abstract: This paper analyzed the repercussions of the COVID-19 pandemic for education in rural communities in which students with a Degree in Rural Education from the Federal University of Minas Gerais (UFMG, Brazil) work and/or reside. The study refers to a broader research, linked to the extension project "Peoples of the Field and the COVID-19 pandemic", created in April 2020. The methodological course of the investigation consisted in the application of online questionnaires in two moments of the pandemic in Brazil (April/May and July 2020). These instruments were answered by 36 (thirty-six) students in the first stage and by 46 (forty-six) students in the second stage. The data were analyzed from the two moments of the research, described and compared to the literature in the rural education area. Thus, at first, a greater movement was observed to keep schools closed and, in the second moment, attempts were observed to establish an emergency remote education with distribution of materials and classes/online contacts. We evidence that the pandemic exposed and accentuated inequalities in school supply in the Brazilian public network, highlighting the historical precariousness of public policies aimed at the education of peasant populations.
\end{abstract}

Keywords: rural education; pandemic; remote education; Covid-19; Brazil. 


\section{Introdução}

Em dezembro de 2019, houve o registro do primeiro caso de um tipo específico de pneumonia na província de Wuhan, na China (Amiri \& Akran, 2020; Qian \& Jiang, 2020). Dada a potencialidade e a expansão dos contágios, a Organização Mundial de Saúde (OMS) classificou a situação como pandêmica. Considerando a dispersão do vírus, o que se viu foi o crescimento exponencial do número de casos e de mortes em todos os continentes. As principais medidas adotadas pelos governos para conter o avanço do vírus foram profiláticas, a saber: lavar frequentemente as mãos, utilizar álcool em gel e se proteger com o uso de máscaras e face-shields até a descoberta de um medicamento eficiente ou vacina para contenção da pandemia da COVID-19.

No percurso de cuidados para com o avanço da pandemia, o que chama a atenção é que também foram impostas e orientadas ações de isolamento social e distanciamento físico, o que incidiu no cancelamento de eventos que aglomeravam pessoas e na suspensão de aulas na Educação Básica e Superior e, depois de certo tempo, a instauração de estratégias de Ensino Remoto Emergencial (ERE). No Brasil, um dos grandes epicentros da doença no mundo, esta forma de continuar ofertando as aulas foi diversa nos diferentes níveis de ensino. Há registros, por exemplo, de ações e métodos utilizados por professores e instituições como a instauração de protocolos de entrega de atividades online e/ou presenciais aos estudantes, famílias/responsáveis, aulas síncronas online, aulas através de programas de televisão, rádio, criação de grupos em aplicativos de trocas de mensagens por celular e lives por meio de redes sociais (Alves, 2020; Almeida \& Alves, 2020).

Ressaltamos que as diferentes estratégias adotadas possuem reveses e são passíveis de críticas contundentes que dizem respeito desde a precarização do trabalho docente até a exacerbação das desigualdades de acesso à educação (Virgínio, 2020). O que podemos dizer é que, em grande parte dos casos, a proposta e a execução desse formato de ERE ressaltaram as desigualdades sociais que já existiam antes da pandemia, principalmente quando nos remetemos às populações mais vulneráveis, como é o caso dos povos do campo. É neste quesito que esta investigação se coloca a saber quais as repercussões da pandemia da COVID-19 para sujeitos e comunidades campesinas no Brasil, tendo como foco de análise a educação.

Torna-se importante destacar que, no percurso da pandemia no Brasil, houve um processo de interiorização dos casos (Batella \& Miyazaki, 2020; Fundação Oswaldo Cruz, 2020). Isso porque os primeiros casos foram registrados nas grandes cidades e, ao longo dos meses, foi-se notando que as pequenas cidades, distritos e comunidades rurais foram atingidos pela pandemia. Esse processo se deve ao perfil de dependência dos pequenos municípios às cidades polo, aos percursos de trânsito e, possivelmente, às fragilidades das políticas públicas de saúde nas pequenas cidades.

\subsection{A educação aos povos do campo no Brasil: alguns apontamentos}

Até meados do século $X X$, havia poucas iniciativas para atender às especificidades educacionais dos povos do campo do Brasil. Com isso, pode-se dizer que o modelo de educação brasileira era quase que exclusivamente voltado para atender 
às necessidades urbanas, haja vista a concepção de que, naquele tempo para o desenvolvimento de atividades agrícolas, não eram necessárias a leitura e a escrita, conforme Antunes-Rocha e Carvalho (2016, p. 16).

Ao longo do século $X X$, inúmeras leis foram promulgadas e projetos implantados sem nenhum resultado expressivo. A precariedade das instalações físicas, a fragilidade dos resultados pedagógicos, a falta de organização administrativa e a presença de professores com pouca formação escolar são características demonstradas por todos àqueles que vivenciam e/ou pesquisam o tema.

As políticas de modernização do campo - referendadas na Revolução Verde e que acarretaram na concentração de terras, mecanização da produção agropecuária, concessão de crédito para grandes empreendimentos, utilização de defensivos agrícolas em larga escala e expansão da fronteira agrícola - impactaram diretamente nas formas de produzir a educação da população rural no Brasil. A responsabilidade da oferta foi transferida do governo federal para os estados e municípios acarretando um aumento da precaridade física, pedagógica e administrativa das escolas rurais. É a partir desse cenário de pouco investimento e de um modelo de escola urbanocentrada que os movimentos sociais, religiosos e sindicais do campo começaram a pautar a necessidade de 'outra' escola no campo.

Durante o Regime Cívico Brasileiro - Ditadura entre 1964 e 1985 - houve o acirramento de conflitos no campo, com líderes religiosos e comunitários sendo perseguidos e mortos, além de uma estagnação nas políticas de Reforma Agrária como forma, inclusive, de conter e silenciar os campesinos (Ribeiro, 2017).

A partir da década de 1980, os movimentos sociais, religiosos e sindicais notaram que transformações das condições de vida e sustento dos povos do campo no Brasil tinham como cerne, além da Reforma Agrária, a necessidade de um paradigma educacional que promovesse o protagonismo dos povos do campo. Entretanto, esse escopo não encontrava representatividade na Educação Rural, por vezes precarizada, descontextualizada e subalternizada a uma 'educação urbana'.

A demanda por um modelo educacional voltado para os povos do campo começou a ganhar força. Esse movimento teve e tem centralidade na construção de uma Escola do Campo que seja capaz de reconhecer e legitimar os modos de vida e de trabalho do camponês, ao mesmo tempo que significa um instrumento de luta por garantia de direitos. Assim, no final da década de 1990 surgiu o movimento conhecido como "Educação do Campo", "uma referência política, teórica e metodológica" que nos informa "a emergência de outra matriz para discutir, implantar e lutar pela escola do campo" (Antunes-Rocha \& Carvalho, 2016, pp. 12-20).

Sublinhamos que a mudança de paradigma de Educação Rural para Educação do Campo foi proposital, uma vez que trouxe para a cena educativa a figura do campesinato, mostrando o foco no protagonismo dos sujeitos do campo, de uma escola de direitos e, ainda, a construção de um projeto de campo articulado a um projeto de sociedade na perspectiva contra-hegemônica. (Rocha, Passos \& Carvalho, 2004). Cabe ressaltar que as demandas comunitárias e dos movimentos populares passaram a pressionar por políticas públicas específicas para os povos do campo, visando à garantia não apenas do acesso e a permanência à educação de qualidade, como também abrangendo a luta pelo direito à terra, ao trabalho, à saúde, entre outras. 
Tais reivindicações ganham respaldo, a partir de então, na Lei de Diretrizes e Bases da Educação Nacional (LDB) em que são reconhecidos a diversidade sociocultural e o direito à igualdade e à diferença (Brasil, 1996). Outrossim, em 2002, houve a aprovação das "Diretrizes Operacionais para a Educação Básica nas Escolas do Campo" (Conselho Nacional de Educação, 2002). Ambas as legislações se constituíram como um grande passo para avanços da Educação do Campo, reforçando a valorização da diversidade dos povos do campo, a formação de professores para e do campo, a promoção e a busca do desenvolvimento sustentável no campo etc.

A partir da aprovação dessas diretrizes e de outras em nível estadual e municipal, vem ocorrendo no Brasil um processo de mobilização e envolvimento social visando à promoção da educação básica para as escolas do campo. Entretanto, ela também ocorreu nas esferas da educação superior com a mobilização de universidades públicas para que houvesse a formação específica de professores para atuar nas escolas, e com isso, surgissem os cursos superiores de Licenciatura em Educação do Campo. (Leal, Dias \& Camargos, 2019)

Embora registremos os avanços na garantia de direitos em relação à educação dos povos do campo no Brasil, há heranças dos tempos da Educação Rural que ainda precisam ser superadas, tais como: escolas sem estrutura básica e requisitos tecnológicos; precarização do trabalho docente; ausência de materiais didáticos voltados às especificidades dos povos do campo; e outras precarizações que não podem ser consideradas ocasionais, pois representam escolhas e agências que direcionam e desvalorizam as pessoas do campo, outrora incidem em fechamento político dessas escolas. A título de exemplo, observamos que:

Na zona rural, 7,4\% das escolas não possuem energia elétrica, 12,7\% não têm esgoto sanitário e $11,6 \%$ não têm abastecimento de água. Na zona urbana, apenas seis escolas não possuem energia elétrica, $0,2 \%$ não têm esgoto sanitário e 0,2\% não têm abastecimento de água; [...] 19,9 mil escolas que oferecem anos iniciais têm apenas um docente atuando nessa etapa. Quase a totalidade encontra-se na zona rural (95,1\%); [...] 89,8\% das escolas com ensino médio estão na zona urbana e 10,2\% na zona rural - menor participação da zona rural em toda educação básica [...] (Instituto Nacional de Estudos e Pesquisas Educacionais Anísio Teixeira, 2017, pp. 7-9)

É neste cenário que a pandemia chegou às populações camponesas, evidenciando todas as precarizações que podem ser consideradas históricas e decorrentes do descaso político e institucional para com a educação nos contextos rurais brasileiros.

\subsection{Percurso Metodológico}

Resgatamos que o objetivo dessa investigação consistiu em analisar repercussões da pandemia da COVID-19 para a educação em comunidades rurais nas quais estudantes de Licenciatura em Educação do Campo de uma universidade pública brasileira trabalham e/ou residem. O estudo foi desenvolvido a partir de ações em um projeto de extensão, tendo caráter exploratório e qualitativo.

Para a contextualização deste estudo, sublinhamos que o curso visa à formação de docentes para atuar em escolas do campo. O curso foi criado a partir de um conjunto de questões que emergiram das lutas dos movimentos sociais e sindicais, em 
diálogo com profissionais da universidade, que entendem e fazem deste um lugar capaz de proporcionar uma educação que não seja apenas aquela oriunda de um conhecimento instituído, mas na sua relação com o saber instituinte (Ribeiro, Carvalho, \& Antunes-Rocha, 2017).

Na referida universidade, o curso é ofertado desde 2005, quando teve início como projeto, sendo, em 2009, regulamentado e incorporado ao conjunto dos cursos da instituição. O currículo é organizado em 04 (quatro) áreas do conhecimento: Ciências Sociais e Humanidades (CSH), Ciências da Vida e da Natureza (CVN); Língua, Arte e Literatura (LAL) e Matemática (MAT). A formação em alternância é o modo como se organizam os espaços e tempos, com articulação entre Tempo Escola - referente à permanência dos estudantes na Universidade nos meses de janeiro e julho para cursarem disciplinas acadêmicas - e o Tempo Comunidade - concernente ao desenvolvimento de atividades diversas pelos estudantes, nos períodos intermediários, com acompanhamento de docentes e monitores/as - estudantes de pós-graduação da universidade. $O$ ingresso dos estudantes é realizado por meio do Exame Nacional do Ensino Médio (ENEM), juntamente com declaração comprobatória de seu vínculo e de sua família com o campo.

O curso possui projetos de ensino, pesquisa e extensão sendo desenvolvidos junto à comunidade acadêmica. Aqui destacamos o projeto de extensão "Povos do Campo e a Pandemia a COVID-19", criado em abril de 2020. Ele funciona em formato remoto e visa mobilizar sujeitos do campo - estudantes, professores, movimentos sociais, sindicatos, entre outros interessados - em torno de ações relacionadas à centralidade da luta contra a COVID-19 e, de modo especial, destacando o papel da ciência neste contexto. A proposta consiste na articulação de diferentes ações em torno do debate e compreensão do momento atual, assim como a socialização e divulgação de informações sobre a temática em questão, além do acompanhamento das comunidades em que os alunos vivem e trabalham.

Dentre as ações propostas no projeto, ressaltamos a realização de mapeamento e acompanhamento de como a pandemia tem afetado os municípios e comunidades dos alunos da LECampo, com o intuito de produzir informações sobre o contexto para possíveis intervenções junto com movimentos sociais, sindicais e demais parceiros do curso. Neste artigo, apresentamos um recorte desta pesquisa, com o foco na Educação.

Para a realização da investigação, enviamos um questionário eletrônico ao conjunto de 128 (cento e vinte e oito) estudantes da LECampo, sujeitos vinculados ao campo e que tinham condições de avaliar as repercussões da pandemia em suas comunidades. A primeira aplicação de questionários foi realizada no período entre 20 de abril a 06 de maio de 2020, ao passo que a segunda aplicação foi feita entre 13 e 19 de julho de 2020. Os questionários foram compostos por perguntas fechadas e abertas, organizadas em 02 (dois) blocos: a) perfil dos estudantes; b) enfrentamento da pandemia da COVID-19 pelos sujeitos e suas comunidades. Sobre o tema abordado neste artigo, realizamos um questionamento, solicitando respostas específicas por nível de ensino: "Sobre a Educação Básica, nível municipal e nível estadual, o que tem sido discutido e/ou feito na sua comunidade?" 
Seguindo recomendações quanto à ética na pesquisa, disponibilizamos um Termo de Consentimento Livre e Esclarecido aos participantes, por meio do qual expressaram autorização da cessão de dados para este estudo. Do total de estudantes do curso, 40 (quarenta) responderam o primeiro questionário e 51 ( cinquenta e um) estudantes responderam o segundo. Ao iniciar o tratamento dos dados, excluímos as respostas dos estudantes que não autorizaram a participação. Sendo assim, foram considerados 36 questionários concernentes ao primeiro momento e 46 questionários relativos ao segundo momento.

Sobre o perfil dos respondentes, a investigação abrangeu estudantes de todas as áreas do conhecimento ofertadas pelo curso, com maior presença das turmas com entrada mais recente: Ciências Sociais e Humanidades (2019) e Língua, Arte e Literatura (2018). Quanto à moradia, todos os respondentes são habitantes de comunidades rurais. No primeiro momento, participaram discentes de 15 (quinze) municípios distintos e, no segundo momento, houve ampliação para 20 (vinte) municípios. Estes encontram-se localizados, principalmente, nas regiões Noroeste, Norte, Jequitinhonha/ Mucuri, Central e Sul do estado de Minas Gerais (ver figura 01).

Na primeira etapa da aplicação dos questionários, contamos com 27 (vinte e sete) mulheres, 08 (oito) homens e 01 (um) respondente não foi identificado quanto ao sexo. Na segunda etapa, participaram 32 (trinta e duas) mulheres, 10 (dez) homens, sendo 4 (quatro) respondentes não foram identificados neste quesito.

Figura 01: Brasil, Minas Gerais: distribuição geográfica destacando municípios de origem dos respondentes da pesquisa

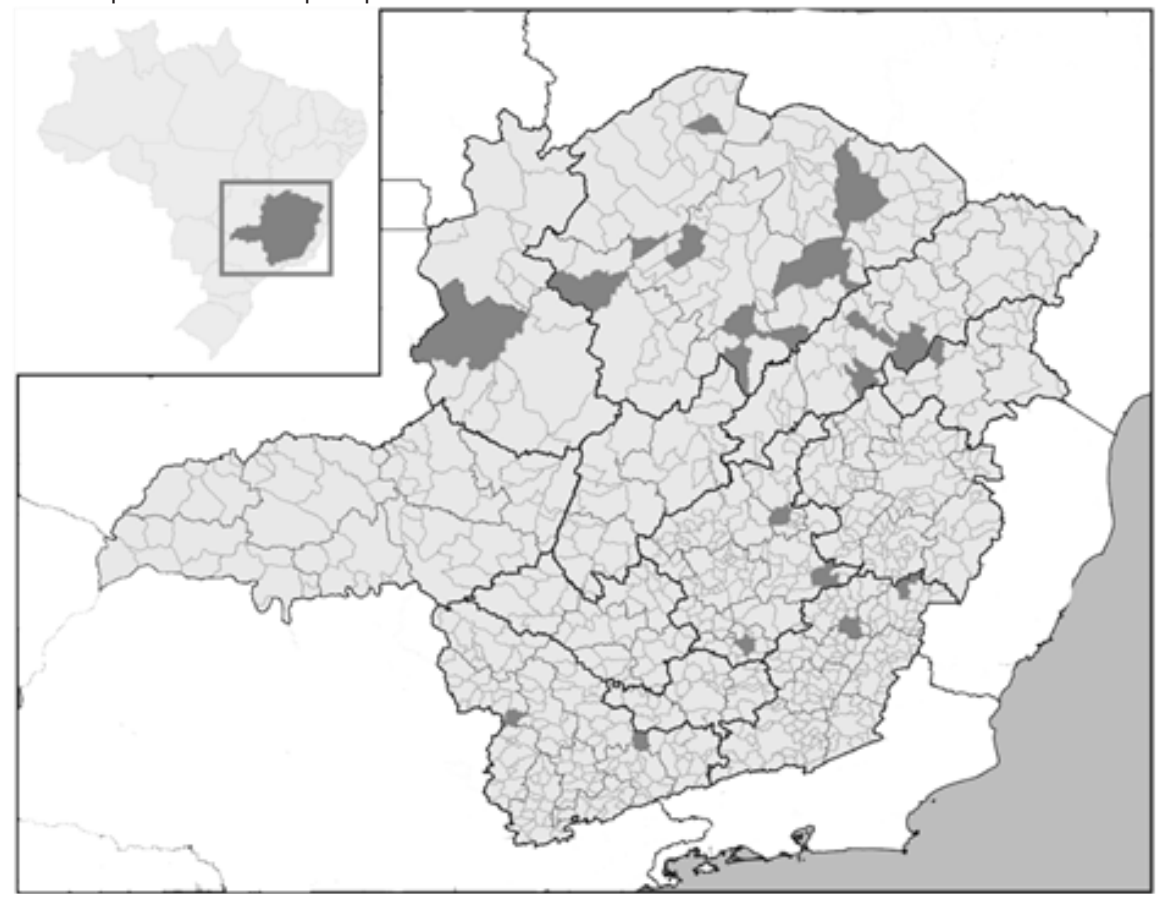

Fonte: Elaboração própria (2021). 
A partir das respostas dadas aos questionários, iniciamos a etapa de tratamento e análise de dados. Os dados foram analisados a partir da distribuição dos dois momentos da pesquisa, descritos e comparados à literatura da área da Educação do Campo. Cabe ressaltar que cada um dos momentos da pesquisa teve suas peculiaridades devido ao andamento da própria pandemia. Assim, a escolha pela caracterização dos dados, de forma descritiva, busca dar visibilidade ao que foi vivenciado em cada um deles, conforme também pode ser visto na pesquisa de Leal e Ribeiro (2020).

\section{Apresentação e análise de dados}

Para iniciar a apresentação dos dados, demonstramos como o sistema de educação está constituído no Brasil. A educação brasileira é regida pela Lei de Diretrizes e Bases da Educação, lei 9.394/96 (Brasil, 1996). Neste documento, consta que a Educação está estruturada em níveis de ensino: Educação Básica (dividida nas etapas da Educação Infantil; o Ensino Fundamental e o Ensino Médio); e a Educação Superior (Figura 02). A oferta da educação pode acontecer de forma privada ou pública, sendo que esta última, pode ficar a cargo dos municípios, estados ou do governo federal.

Figura 02: Organização da Educação no Brasil segundo a Lei 9.394/96.

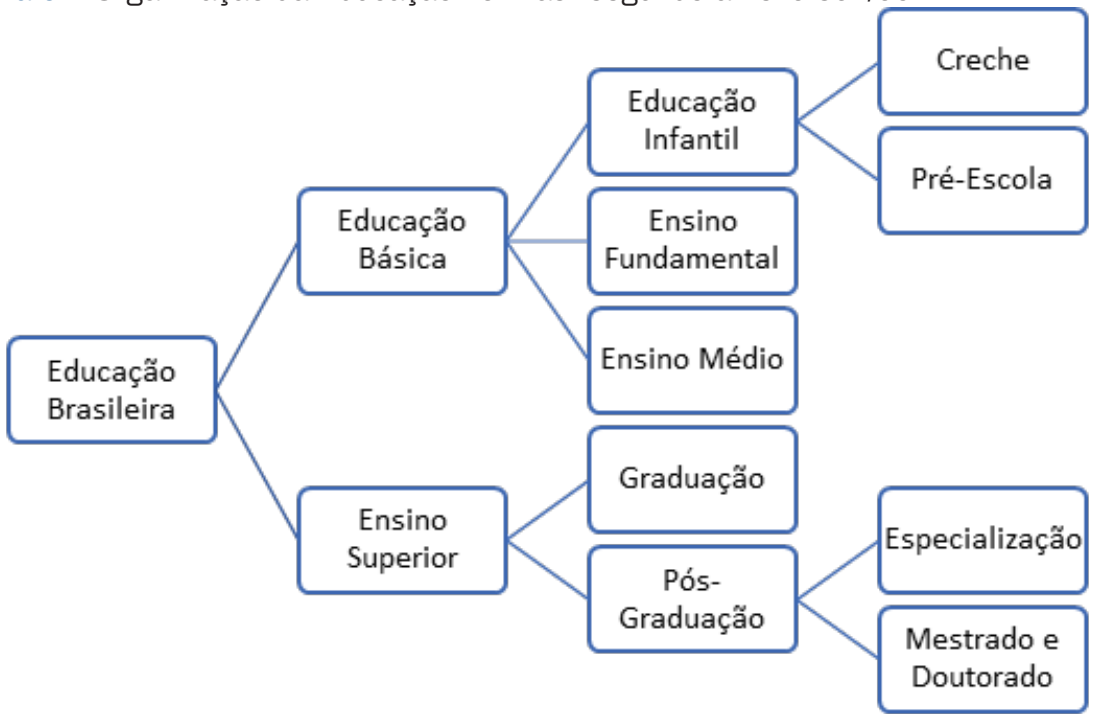

Fonte: Brasil (1996).

Quanto à oferta da Educação Básica durante a pandemia, sublinhamos a aprovação, em 28 de abril de 2020, do Parecer CNE/CP nº 5/2020 (Conselho Nacional de Educação, 2020). Este congrega diretrizes para orientação dos estados, municípios e escolas quanto a normas gerais e práticas a serem adotadas, com destaque para a reorganização do Calendário Escolar e a possibilidade de cômputo de atividades não presenciais, visando ao cumprimento da carga horária mínima anual devido à pandemia. Tal aspecto ficou sob responsabilidade dos diferentes sistemas de ensino. 
Em concordância com Oliveira (2020, p. 4), apontamos que, especialmente no início dos processos, as ações passaram a ser "realizadas de maneiras pouco ou nada planejadas e de modo emergencial", com a adoção do ERE.

No estado de Minas Gerais, foi aprovada a Resolução SEE n 4310/2020 (Secretaria de Estado de Educação, 2020), divulgada em 22 de abril de 2020, que institucionalizou o Regime Especial deAtividades Não Presenciais (REANP) ${ }^{1}$. O mesmo foi organizado em três frentes: 1) Planos de Estudo Tutorado (PETs), apostilas mensais que contém um conjunto de atividades e orientações de estudos (disponibilizado online ou no formato impresso), 2) Programa de TV "Se Liga na Educação" e 3) Aplicativo Digital Conexão Escola. Alguns municípios adotaram este mesmo regime em suas escolas da rede pública, de forma parcial ou total. Outros adotaram estratégias distintas, com produção de materiais e orientações de estudo centralizadas nas Secretarias de Educação ou nas próprias escolas, alcançando diferentes repercussões e resultados junto à comunidade escolar.

\section{Primeiro momento}

Referimo-nos ao primeiro momento dessa pesquisa relativo à primeira coleta de dados, entre abril e maio de 2020. Cabe ressaltar que, nesse momento, viviam-se as primeiras semanas de instauração das preocupações e ações sobre a pandemia da COVID-19 no Brasil e no Estado de Minas Gerais. A principal ação notada foi a interrupção das atividades escolares tanto nas redes municipais quanto estaduais. Imagina-se que essa interrupção tinha como visão de futuro que a pandemia logo seria superada e, diante disso, suspender as atividades por pouco tempo, adiantar as férias de julho ou esperar para planejar alternativas pedagógicas eram vistas como necessárias para resolver a situação.

Assim, a partir das respostas dos participantes da pesquisa identificamos que, sobre a educação a nível estadual, foi relatado que a maioria das escolas estaduais estavam totalmente fechadas, ou seja, sem nenhuma atividade de ensino sendo realizada. Essa interrupção gerou certa insegurança, conforme relatos:

Aescola mantém sem funcionamento. Há informações por parte dos educadores e lideranças da mesma, de que não se sabe quando as aulas e a normalidade no ensino voltarão. A menos que essa pandemia acabe. (Sexo masculino, Icaraí de Minas).

Até onde possuo informação, a rede estadual ainda não divulgou como serão realizadas atividades a distância. Os alunos ainda aguardam ansiosamente para dar início aos trabalhos em casa." (Sexo feminino, Rio Pardo de Minas).

Uma das participantes comparou a situação das escolas a nível estadual com a situação das mesmas a nível municipal:

Como dito anteriormente, todas as atividades nas escolas estão paradas, porém, constantemente, há incertezas quanto à postura do governo sobre a educação, salário dos servidores, como ficará o ano letivo, os estudantes do $3^{\circ}$ ano do ensino médio e o ENEM, a situação dos servidores designados, o retorno ou não das atividades presenciais, como vai funcionar o teletrabalho e

\footnotetext{
${ }^{1}$ Disponível em: https://estudeemcasa.educacao.mg.gov.br/.
} 
tantos outros questionamentos. Os servidores têm utilizado bastante o grupo de WhatsApp das escolas para comunicar entre si e dividir as angústias e anseios frente essa pandemia (Sexo feminino, Piranga).

Dessa forma, notamos que, referente à educação a nível municipal, a situação era semelhante à educação a nível estadual, com a maioria das escolas fechadas no momento de aplicação do primeiro questionário e sem nenhuma atividade escolar sendo realizada por professores e estudantes.

A suspensão das aulas foi uma medida adotada de maneira generalizada, contudo, despertou avaliações diversas e controversas por parte das comunidades escolares. De modo geral, para grande parte das comunidades, essa parece ter sido considerada a atitude mais acertada para evitar o contágio, a exemplo do que descreve uma participante, que entendeu como positivo o fato das escolas estarem fechadas: "As escolas estão paradas para o bem de todos" (Sexo feminino, Rio Pardo de Minas).

Uma situação peculiar foi indicada por uma das participantes: "Até o momento nada, uma vez que já tem muito tempo, desde antes da pandemia, que a aulas estão paradas. Ainda não tomaram medidas." (Sexo feminino, Icaraí de Minas). A este respeito, salientamos que, em algumas escolas estaduais e municipais a retomada do ano letivo estava prevista para o início do mês de fevereiro - portanto, pouco mais de um mês antes da suspensão das aulas devido à pandemia tal retorno não aconteceu. Dentre os motivos, citamos: dificuldades e/ou indisponibilidade do processo de contratação de novos docentes (temporários e, em menor número, permanentes, via aprovação em concurso público); paralisações e/ou greves de profissionais da Educação devido a reivindicações de melhores condições de trabalho, reforma de escolas por motivos diversos, entre outros.

Desde já, se apontava a necessidade de retomada de atividades pós início da pandemia, entretanto, uma participante apontou dificuldade devido à impossibilidade de locomoção na comunidade e acesso à internet: "Até o presente momento, nenhuma iniciativa na comunidade foi realizada na educação eásica, devido à dificuldade de locomoção dos profissionais de educação e estudantes e ao acesso restrito à internet." (sexo feminino, Capelinha-MG). Outro participante descreveu situação semelhante, apresentando, ainda, dificuldades quanto à relação família-escola nesse contexto, com destaque para dificuldades dos pais em auxiliar os filhos em um possível retorno remoto - aspecto marcante em diversas comunidades rurais no país, devido ao descaso histórico com a oferta educativa à estas populações (Antunes-Rocha \& Carvalho, 2016) -, e falta de acesso à internet - outro aspecto crucial a ser salientado, devido à exclusão digital destas localidades, como apontado por uma estudante:

Os pais dos estudantes estão preocupados com a situação, mas não sabem ao certo o que vai acontecer. A maioria dos estudantes da minha comunidade está sem estudar em casa pois a maioria não tem acesso à tecnologia e os pais não sabem orientá-los para estudar em casa. Todas as atividades a nível municipal e estadual estão paradas. Os diretores e secretário municipal têm tido reuniões com responsáveis pela SRE [Superintendência Regional de Ensino] de Conselheiro Lafaiete. (sexo feminino, Piranga). 
Além disso, uma das participantes apontou uma situação vivida em algumas comunidades do campo anterior à pandemia: a falta de escolas nestas localidades, em função da nucleação das escolas situadas no meio rural (Gonçalves, 2010), e a necessidade de se deslocar para outras comunidades para ter acesso à educação a nível estadual, especialmente ao Ensino Médio:

Na nossa comunidade não possui escola estadual, os estudantes frequentam escolas em comunidades vizinhas. Está em discussão nesse momento entre os moradores, dúvidas a respeito das aulas online, se vão funcionar, quando vai começar e quais vão ser os procedimentos. Até então as escolas estaduais não estão mandando material para estudo (sexo feminino, Capelinha).

A este respeito, é fundamental destacar que, no Brasil, vem ocorrendo a nucleação de escolas situadas no meio rural, processo que envolve o fechamento de escolas de menor porte em pequenas comunidades rurais e o uso do transporte para que os estudantes sejam direcionados para escolas geralmente situadas em núcleos urbanos ou, com menor incidência, em outras comunidades rurais. Entendemos que mesmo que a pandemia tenha trazido dificuldades educacionais e pedagógicas para a educação em contextos rurais, a precarização das escolas do campo no Brasil, o fechamento de escolas nas comunidades rurais e a marginalização da oferta escolar para os povos campesinos trazem em si marcas históricas, as quais a pandemia só fez reforçar. A ausência de escola na comunidade, a necessidade de deslocamento para estudar nas sedes municipais, a fragilidade estrutural e de acesso à internet são apenas sintomas do descaso e ausência de políticas públicas que atendam especificidades dessas populações (Antunes-Rocha \& Carvalho, 2016; Ribeiro, 2017).

Também neste primeiro momento de ações, há relatos de disponibilização de materiais impressos para os estudantes na tentativa de continuidade do processo de aprendizagem em casa:

Em minha comunidade os professores têm elaborado atividades para passar aos alunos, para que eles possam continuar em casa, a ver os conteúdos que seriam passados na sala de aula. Essas atividades são deixadas nas escolas e os pais buscam e levam para seus filhos em casa, assim como tem sido feito na rede municipal. (Sexo feminino, Rio Pardo de Minas).

Apenas um participante informou que as atividades escolares estavam ocorrendo a partir dos PETs e as aulas estavam ministradas pelos professores por meio da internet, com destaque para a criação de "possíveis métodos para estimular a aprendizagem dos alunos" (Sexo masculino, Icaraí de Minas). Outra participante afirmou que o estudo estava ocorrendo pelos PETs e as orientações estavam dadas pelos professores por meio da internet: "foram feitos grupos de Whatsapp para serem repassadas as atividades aos estudantes" (Sexo feminino, Rio Pardo de Minas).

Por sua vez, diante da constatação de que o desenvolvimento do ERE seria dificultado, em diversas comunidades rurais, devido à precariedade de acesso à internet por muitos de seus membros, algumas ações começaram a ser adotadas por membros da escola relativas à disponibilização de atividades impressas aos estudantes.

Em escolas de redes municipais, quanto à elaboração dos materiais a serem destinados aos estudantes, tanto no primeiro momento como no segundo, há relatos de que equipes pedagógicas, de gestão e, especialmente, de docentes, se dedicavam 
à elaboração e organização do material, seja no âmbito da própria escola, seja no âmbito da rede de ensino, com produção de atividades para o conjunto de escolas. Também, há relatos referentes à adesão, por algumas redes municipais, à proposta elaborada pela Rede Estadual de Educação. Neste caso, destaca-se a adoção dos PETs e, em menor número, às videoaulas, transmitidas pela internet e pela emissora de televisão estatal Rede Minas.

Quanto à prática de entrega de materiais aos estudantes, observamos que, alguns casos, a mesma foi conjugada com ações relativas ao uso de recursos tecnológicos, seja para entrega dos materiais online, seja para que professores passassem a dar orientações pela internet quanto à realização das atividades. Os participantes da pesquisa destacaram algumas distinções que começaram a ser estabelecidas quanto aos suportes pedagógicos acessíveis aos estudantes. Os discentes passaram a ser divididos entre aqueles que possuíam e não possuíam acesso à internet, sendo este último grupo considerado 'prejudicado' em seu direito à educação com qualidade:

Nas escolas municipais, estão sendo entregues nas casas dos alunos atividades para o mês. Já foi entregue duas vezes. No mês de abril, os alunos não tiveram nenhum suporte para responder as atividades. Os que possuem Internet fizeram pesquisando (na maioria dos casos, pegando respostas prontas). Os que não possuem acesso à internet não sei como estão fazendo. Acredito que responderam apenas a minoria [das perguntas], pois não tem acesso a explicação nenhuma e nem as respostas prontas do Google. Já neste mês de maio, a direção criou um grupo de WhatsApp com os alunos que possuem internet e com os todos os professores, para que os alunos possam tirar dúvidas referente as atividades. Com isso, mais uma vez, os alunos que não têm acesso à internet ficam prejudicados. (Apesar de que este grupo, na minha concepção, mais atrapalha do que ajuda, pois como são adolescentes perdem muito tempo com conversas paralelas) (Sexo feminino, Rio Pardo de Minas).

Neste momento da pesquisa não foram descritas situações nas quais professores ministravam aulas virtuais. Com a chegada dos materiais às casas dos estudantes, também começaram a ser sinalizadas as orientações dadas pelas famílias no desenvolvimento das tarefas.

O que foi visto e descrito pelos participantes da pesquisa, nesse primeiro momento, foi, de início, a suspensão das aulas como estratégia de proteção e enfrentamento a pandemia tanto no nível municipal quanto no estadual. Com o passar das semanas, diante da necessidade de continuidade das atividades escolares e a imposição das restrições sociais e de distanciamento, foram iniciadas práticas pedagógicas com a disponibilização de materiais para estudo (impressas e por meios digitais), além de orientações via aplicativos de mensagens. Essas primeiras ações, mesmo que insipientes e limitadas, demonstraram a tentativa de manter o vínculo educacional e relacional com os estudantes e com a escola.

Pensando no contexto educacional do campo, os relatos dos participantes da pesquisa trazem à cena as iniquidades de acesso à educação as quais, como já dissemos, são anteriores à pandemia da COVID-19. A internet, neste primeiro momento utilizado como principal ferramenta para manutenção das atividades, ressaltou as 
iniquidades, haja vista o que foi identificado pela ALMG (Assembléia Legislativa de Minas Gerais, 2020) que o ensino não presencial de ensino não presencial excluiu mais de 700 mil estudantes em Minas Gerais.

\section{Segundo momento}

No segundo momento da pesquisa, realizado em julho de 2020, tanto em nível municipal quanto estadual houve a indicação de uma primazia de respostas sobre as atividades impressas disponibilizadas pelas escolas, seguidas por orientações dadas pelos professores por meio da internet, esta última em menor número. Reitera-se, como antes apontado, que a elaboração de materiais no âmbito das escolas e, também, a adoção do REANP, parece ter se acentuado neste momento.

Quanto à entrega de materiais impressos, um sujeito da pesquisa apontou que a educação a nível estadual é, também,

[...] um assunto pouco comentado na comunidade. Na verdade, há várias reclamações pois os pais estão com receio que, apesar das apostilas que os filhos estão recebendo, tem medo deles ficarem prejudicados e não aprenderem o conteúdo, já que muitos não tem internet em casa para dar maior suporte. (Sexo feminino, Rio Pardo de Minas).

Quanto à distribuição dos materiais especificamente nas escolas municipais, chamou nossa atenção a diversidade de modos como as escolas fizeram com que chegassem aos estudantes e, também, embora em menor número, as estratégias utilizadas para que tais materiais retornassem à escola, visando, talvez, que as atividades fossem vistas, corrigidas e/ou avaliadas pelos docentes. Salientamos que, em alguns casos, houve contabilização da frequência escolar por meio do registro da entrega destas atividades, visando à validação do ano letivo.

Sobre a mobilização da comunidade escolar na organização da logística de entrega, recepção e devolução dos materiais, se percebeu que este aspecto passou a ser observado e revisto constantemente na medida em que a pandemia foi avançando nas diferentes localidades:

A direção, juntamente com os professores, está desenvolvendo apostilas com diversas atividades para que os alunos possam resolver em suas casas. Essas apostilas ficam com eles pelo período de um mês. Logo em seguida, os responsáveis pelos alunos vão até a escola devolver e pegar novas apostilas. (Sexo feminino, Grão Mogol)

"Está tendo aulas para as crianças em casa, as professoras levam as atividades nas casas dos alunos" (Sexo feminino, Santa Fé de Minas)

"Têm sido realizadas atividades impressas, que mensalmente são entregues pelo motorista do ônibus." (Sexo feminino, Rio Pardo de Minas).

Nesta logística, os professores assumiram um papel relevante na entrega, entretanto, verificamos o envolvimento de outros profissionais, como motoristas do transporte escolar. Há, também, relatos específicos sobre funcionamento da busca e devolução de materiais na escola pelas famílias, por responsáveis e/ou por estudantes, bem como os cuidados demandados para tanto: 
As atividades estão sendo entregues para os pais e compartilhada em grupos do Whatsapp que pais e responsáveis participam para serem repassadas para os alunos" (Sexo feminino, Icaraí de Minas).

[...] em casos de alunos que não tem a internet, são entregues as atividades na secretaria da escola, desde que o aluno ou responsável esteja usando máscara. (Sexo feminino, Rio Pardo de Minas).

Em relação a Educação Básica Nível Estadual, está sendo desenvolvido o PET. Também foram criados grupos em redes sociais para facilitar a comunicação e dessa forma os alunos tiram possíveis dúvidas com os professores. O material fica disponibilizado na escola e também são entregues nos pontos de ônibus. Alguns alunos constataram que no material havia matérias que eles já haviam estudado em anos anteriores. (Sexo feminino, Capelinha).

[...] na escola estadual os alunos têm aulas online e recebem o material em casa. E o auxílio de 50 reais mensais para a merenda. (Sexo feminino, Rio Pardo de Minas)

Nesses trechos, uma das primeiras opções de contato e envio de materiais consistiu na utilização da internet, com destaque para o uso do aplicativo de troca de mensagens WhatsApp®. Tal uso encontrou respaldo porque o acesso a celulares pareceu ser mais comum do que a tablets e computadores, por exemplo. Outra opção consistiu na entrega de materiais impressos, destinada apenas a estudantes e famílias que apresentavam impossibilidade de acesso à internet. Quanto a isto, salientamos que tal estratégia esteve bastante presente em diferentes comunidades rurais do estado de Minas Gerais, dada a elevada exclusão digital destas populações, conforme já apontado. No momento da implantação do REANP, circulou a informação de que mais de 700 mil estudantes retomariam os estudos no novo formato sem acesso à internet, a equipamentos eletrônicos adequados e a sinal da emissora de televisão responsável pela veiculação das videoaulas (Assembléia Legislativa de Minas Gerais, 2020).

Ainda verificando estes trechos de fala dos participantes, notamos uma situação peculiar neste segundo momento de aplicação da pesquisa em nível municipal: o envio não somente de materiais, mas de uma contribuição financeira para que as famílias do campo complementassem a alimentação. Ressaltamos a importância dessa ação que, ao verificar que estes estudantes tinham no espaço escolar uma possibilidade de se alimentar, alguns municípios e no estado de Minas Gerais instituíram políticas para a distribuição de alimentos e/ou de benefícios para complementação de renda.

Embora em menor número, também foram mencionadas aulas ministradas via internet por professores e videoaulas transmitidas via canal de TV estatal pela Rede Estadual de Educação. Novamente, destaca-se que tal ação é bastante limitada, especialmente devido à ausência de acesso à internet e baixa cobertura televisiva no estado:

A educação Municipal está na terceira etapa de entrega de atividades xerocadas para os alunos. Os professores preparam atividades para quatro semanas. Prepara o material, tiram o xerox do mesmo. Essas atividades são entregues a um responsável em um envelope, mediante a todas as medidas preventivas. Os professores orientam os alunos via grupo de WhatsApp. O desafio é que nem todos os estudantes têm acesso a internet. Os alunos da rede municipal também têm acesso aos PETs (Sexo feminino, Simonésia). 
Grupos de WhatsApp, da coordenação da escola, e recentemente, devido à pressão dos pais, que não estavam conseguindo ensinar as atividades para seus filhos, foi criado um grupo de WhatsApp no qual as professoras explicam o conteúdo do dia. (Sexo feminino, Rio Pardo de Minas)

Tem-se aderido ao programa PET e aulas pela internet. (Sexo masculino, São Domingos do Prata).

No contexto do REANP, os participantes descreveram essas orientações remotas de diferentes modos, por exemplo: suporte de professores, orientação pedagógica, sugestões de pesquisas online e realização de conversas. O uso de aplicativos de celular reapareceu no contexto dessa orientação de estudos, como descrevem outros participantes:

Devido à falta de acesso às comunidades do município e também a falta de acesso à internet e etc., os professores têm tido dificuldades de prestar apoio ou um acompanhamento mais efetivo sendo assim os alunos estão desligados da escola sem muito o que fazer tanto por parte dos mesmos quanto pelos professores. (Sexo feminino, Rio Pardo de Minas).

Estão acontecendo atividades e realizações de diálogos via WhatsApp, mas nem todos os alunos dispõem deste meio. (Sexo masculino, Rio Pardo de Minas).

Está tendo aula online, mas a maioria não tem acesso à internet e a desigualdade social está cada dia maior. (Sexo feminino, Santa Fé de Minas).

Como visto nos trechos, os participantes da pesquisa salientaram a dificuldade de acesso de estudantes das comunidades para acompanharem as aulas online. Embora tenhamos identificado que há uma dificuldade de acesso à internet por parte dos sujeitos do campo, foi notado que essa característica também persiste nas áreas de maior vulnerabilidade socioeconômica das cidades, sendo um dos principais desafios para a implantação e execução do ERE (Alves, 2020; Leal \& Ribeiro, 2020).

Para além do não acesso à internet, percebeu-se, também, que alguns estudantes não possuíam equipamentos para uso pessoal. Além de dividir um mesmo aparelho com um ou mais adultos, também, em alguns casos, passaram a compartilhar com outros estudantes e familiares, situações também desafiadoras para o processo de ensino-aprendizagem neste contexto. Mesmo com a identificação de receios por parte de pais/responsáveis, algumas das respostas enfatizam as ações da comunidade escolar para oportunizar esses materiais impressos aos estudantes, principalmente para aqueles que não têm acesso à internet.

Os alunos são responsáveis por pegar suas atividades na escola com um funcionário da instituição, os pais não sabem como proceder para ajudar seus filhos sem contar que há trabalhos da roça a serem desenvolvidos sem contar que está na época da colheita de café. (Sexo feminino, Piranga).

Os alunos estão acompanhados de maneira improvisada, devido à falta de acesso à internet. Os pais estão tendo que se desdobrar para ajudar os filhos, juntamente com o apoio dos professores da escola que mandam o material impresso para os demais. Porém, muitos pais não têm conhecimento necessário para ajudar os filhos (Sexo masculino, Icaraí de Minas). 
Como evidenciado pelos participantes, neste segundo momento ainda vigoravam o não acesso aos materiais impressos, especificamente por algumas famílias do campo. O não acesso, a dificuldade familiar de auxílio nos estudos tutorados e a dificuldade de conjugação com a vida no campo se somaram a peculiaridades impostas pela pandemia no contexto escolar campesino.

Entretanto, alguns dos participantes descreveram a presença de suporte das famílias na orientação dos estudos em casa, seja lendo e auxiliando os estudantes, na logística e nos estudos, mesmo com dificuldades diversas:

Os alunos estão com orientação dos pais lendo algumas atividades e realizando algumas tarefas impressas (Sexo feminino. Piranga)

Fica sob responsabilidade dos pais buscar as atividades dos filhos na escola. Muitos estão tendo dificuldades para auxiliar seus filhos, pois alguns são analfabetos, outros acham que as atividades são difíceis e encontram dificuldades para manter a concentração de seus filhos. (Sexo feminino. Piranga)

A dificuldade quanto ao suporte para realização das atividades tem relação com a precariedade do acesso de estudantes a livros didáticos, com as condições precárias de alguns professores em relação a recursos pessoais, como celulares e internet para desenvolvimento de seu trabalho e não fornecidos pelo poder público municipal e estadual, além da ausência de professores devido ao corte de contratos de docentes temporários em alguns municípios. Esses problemas já estavam acentuados nas escolas do campo bem antes da pandemia e ficaram escancarados neste 'novo' contexto:

A direção da escola está enviando mensalmente atividades para que os alunos respondam nas suas residências, porém, sem nenhuma explicação de professores e em algumas disciplinas nem o livro didático os alunos possuem. Os professores contratados que são uma quantidade bem elevada, os contratos foram suspensos. Na escola na qual as minhas irmãs estudam há apenas 2 professores concursados, então, os alunos não tem um suporte nem online, possui apenas um grupo de WhatsApp "para tirar dúvidas", mas mesmo se funcionasse estes grupos não adiantariam muita coisa, pois apenas duas disciplinas teriam suporte. Até hoje, nunca recolheram nenhuma atividade. Apenas mandam para os alunos fazerem. (Sexo feminino, Rio Pardo de Minas)

No momento, as presenciais aulas estão paralisadas, há apenas um acompanhamento feito pelos profissionais da Educação a distância sem as devidas condições, estrutura ou recursos necessários para o ensino-aprendizagem. Traduzindo, pouco tem sido feito pois muitos não têm acesso a plataformas, internet ou algo semelhante para que possam aprender ou estar em dia com os estudos e etc. (Sexo feminino, Rio Pardo de Minas).

Por fim, houve o relato de um dos participantes sobre uma prática peculiar no contexto da pandemia: aulas particulares lecionadas por professores. Destacamos esta ação devido ao fato de contrariar regras de distanciamento e, por vezes, não ser uma atividade com amparo trabalhista e social que garantem direitos aos professores, embora sendo uma atividade que permitiu que alguns destes sobrevivessem durante a pandemia devido ao rompimento dos vínculos trabalhistas. 
Algumas professoras estão dando aulas particulares para alunos, apesar de ser uma saída que vai contra as medidas de proteção." (Sexo masculino, Icaraí de Minas).

Sobre esta prática, compreendemos que, diante de dificuldades vividas por diversas famílias e/ou da ausência e/ou precariedade de estratégias oriundas de políticas públicas, conforme sinalizado anteriormente, nota-se, pois, embora em pequeno número, a adoção de estratégias individuais que colocam em risco a proteção à vida em tempos de pandemia visando à manutenção do processo de ensino-aprendizagem e do acesso de qualidade à educação, entendida por muitas famílias das camadas populares como um dos únicos caminhos possíveis para a ascensão social no país.

\section{Considerações finais}

Para finalizar este texto, reiteramos os desafios sociais, econômicos e educacionais que a pandemia da COVID-19 trouxe. Nessa pesquisa, que acompanhou o desenvolvimento de um projeto de extensão junto às populações campesinas, verificamos dois momentos dos impactos das restrições sociais impostas para a área educacional no estado de Minas Gerais, no Brasil. Assim, a partir dos dados coletados, é possível notar que, no primeiro momento, em meados de abril/maio de 2020, houve um movimento de manter as escolas fechadas e, no segundo momento, em julho de 2020, foram observadas tentativas de instaurar um modelo de ensino remoto com distribuição de materiais, impressos e/ou digitais, e aulas/contatos online.

Evidenciamos que a pandemia expôs e acentuou as desigualdades na oferta escolar na rede pública brasileira, sobressaltando a precariedade histórica das políticas públicas destinadas à educação das populações campesinas. Entretanto, concordamos com Oliveira (2020) sobre a necessidade de reconhecimento do "caráter de excepcionalidade" ao atual momento. Porém, também entendemos ser necessário salientar que, no período pré-pandemia, não contávamos com preparação mínima para encarar o desafio que nos foi colocado coletivamente.

A formação de professores e, também, as condições infraestruturais das escolas do campo pouco ou nada estavam preparadas para a lida com o mundo digital e suas possibilidades de uso e apropriação concretas no campo educacional, por exemplo. A oferta educativa para sujeitos do campo, de modo especial, padece com a descontinuidade de políticas públicas que atendam suas especificidades, relativas à formação docente, à produção, à distribuição e uso de materiais didáticos, às suas condições materiais, à inclusão digital, entre outros aspectos.

Ressaltamos que, a partir dos dados coletados, em nenhum momento da pesquisa foi visto que a educação nos contextos rurais, que guarda sua especificidade pedagógica, política e de sujeitos enquanto um direito dos povos do campo, conforme legislação instituída no país, foi tratada com tal singularidade diante da pandemia. A nosso ver, isso impacta diretamente na qualidade de ensino ofertada e nas perspectivas futuras de desenvolvimento dos sujeitos do campo brasileiro.

Para além dessa situação, a necessidade de implantação de um ensino remoto emergencial trouxe à tona muitas questões que ainda devem suscitar discussões: como construir processos educativos mediados por plataformas online? Como manter a atenção de crianças, adolescentes e adultos neste 'novo' formato? Como fazer com 
que todos tenham acesso com qualidade às aulas? Como garantir a aprendizagem? Como manter a relação estudante-professor em um contexto de isolamento social mediado? Como manter a saúde mental de estudantes e professores diante das restrições impostas e, por vezes, diante da exacerbação das rotinas 'em casa'? Se estas questões têm mobilizado professores e sujeitos da educação diante da situação pandêmica, convidamos a toda a sociedade a respondê-las também observando as especificidades da educação para/com/dos povos do campo.

\section{Referências}

Almeida, B. \& Alves, L. (2020). Lives, Educação e Covid-19: estratégias de interação na Pandemia. interfaces Científicas - Educação, 10(1), 149-163. https://doi.org/10.17564/23163828.2020v10n1p149-163

Alves, L. (2020). Educação Remota: entre a ilusão e a realidade. Interfaces Científicas - Educação, 8(3), 348-365. https://doi.org/10.17564/2316-3828.2020v8n3p348-365

Amiri, A. \&Akran, M. (2020). COVID-19: The challenges of the human life. Social work \& social sciences rewiew, 17(1). Recuperado de https://bit.ly/3fMGhAO

Antunes-Rocha, M. \& Carvalho, C. (2016). Caderno II: Educação do Campo: histórico, princípios, conceitos e práticas. Belo Horizonte: UFMG/FaE.

Assembléia Legislativa de Minas Gerais. (08 de 06 de 2020). Ensino não presencial exclui mais de 700 mil alunos. Assembléia Legislativa de Minas Gerais. Recuperado de https://bit.ly/34qHpou

Batella, W. \& Miyazaki, V. (2020). Relações entre rede urbana e Covid-19 em Minas Gerais. Hygeia: Revista Brasileira deGeografia Médica e da Saúde(Edição Especial: Covid-19), pp. 102110. https://doi.org/10.14393/Hygeia0054622

Brasil. (1996). Lei 9.394 de 20 de dezembro de 1996. Lei de Diretrizes e Bases da Educação Nacional. Recuperado de https://bit.ly/3ylaikF

Conselho Nacional de Educação (2002). Parecer n. 36/2002. Brasília.

Conselho Nacional de Educação (2020). Parecer CNE/CP no. 5/2020. Fonte: Ministério da Educação. Recuperado de https://bit.ly/340W5nU

Fundação Oswaldo Cruz. (05 de maio de 2020). Covid-19: tendência de interiorização aumenta e pode gerar mais pressão sobre grandes centros. Recuperado de https://bit.ly/2SAS5hA

Gonçalves, G. B. (2010). Nucleação das escolas rurais. Em D. Oliveira, A. Duarte \& L. Vieira, Dicionário: trabalho, profissão e condição docente. Belo Horizonte: UFMG/Faculdade de Educação.

Instituto Nacional de Estudos e Pesquisas Educacionais Anísio Teixeira. (2017). Censo Escolar da Educação Básica 2016. Brasília: Ministério da Educação. Recuperado de https://bit. Iy/3oWVjli

Leal, Á. \& Ribeiro, L. (2020). Práticas religiosas, Covid-19 e campesinato: uma análise em dois momentos da pandemia a partir de um projeto de extensão. Revista Brasileira de Educação do Campo, e10818. https://doi.org/10.20873/uft.rbec.e10818

Leal, Á., Dias, A. \& Camargos, O. (2019). Cartografia das licenciaturas em Educação do Campo no Brasil: expansão e institucionalização. Em M. Molina, \& M. Almeida-Martins, Formação de formadores: reflexões sobre as experiências da Licenciatura em Educação do Campo no Brasil (pp. 39-53). Belo Horizonte: Autêntica.

Oliveira, V. H. (2020). "O antes, o agora e o depois": alguns desafios para a educação básica frente à pandemia de covid-19. Boca: Boletim de Conjuntura, 9(3). Recuperado de https://bit. ly/3vz3Q70

Qian, M. \& Jiang, J. (2020). COVID-19 and social distancing. Journal of Public Health (Berl.). https:// doi.org/10.1007/s10389-020-01321-z 
Ribeiro, L. P. (2017). O campo, a violência e a Educação do Campo. Rio de Janeiro: Gramma.

Ribeiro, L., Carvalho, C. \& Antunes-Rocha, M. (2017). Representações sociais em movimento: uma análise de duas pesquisas no âmbito da Educação do Campo da FaE-UFMG. Revista Educação e Cultura Contemporânea, 14(37), 343-366.

Rocha, E., Passos, J. \& Carvalho, R. (2004). Il Conferência Nacional de Educação do Campo: texto Base. Luziânia.

Secretaria de Estado de Educação (2020). Resolução SEE-MG 4.310/2020. Secretaria de Estado de Educação - Minas Gerais. Recuperado de https://bit.ly/3wEr6jR

Virgínio, A. S. (2020). Educação, Desigualdade e COVID-19. Fonte: Universidade Federal do Rio Grande do Sul. Recuperdo de https://bit.ly/2RRX0e3 